\title{
Measuring the clinical impact of thoracic computed tomographic scanning
}

\author{
Mark O Turner
}

The usefulness of thoracic computed tomographic (CT) scanning in the management and clinical outcome of patients is difficult to measure. Thoracic CT scans are not stand alone tests but are used in conjunction with other investigations and diagnostic tests. Each of these tests contributes positive or negative information to the clinical management. A useful diagnostic test is accurate, able to facilitate the application of specific treatment, and contributes to a better clinical outcome for the patient. ${ }^{1} \mathrm{Be}-$ cause of these characteristics, the impact of diagnostic tests on clinical outcomes is less obvious than therapeutic interventions designed to show superiority or equivalence of effect. The greatest impact from CT scanning would be expected in clinical situations where there is significant uncertainty about diagnosis, extent of disease, or prognosis.

Although thoracic CT scanning has greater spatial and contrast discrimination than chest radiography, more accurate diagnostic information does not always lead to better outcomes. New information from a diagnostic test such as CT scanning may not change procedures or management plans due to pre-test probabilities that are already high or very low. Should CT scans be done when there is a low likelihood of changing management decisions? In part, this depends on the accuracy (sensitivity and specificity) of the CT scan and whether efficacious treatment exists for a specific clinical problem. The CT diagnosis of pulmonary embolism is a clinical situation where, compared with pulmonary angiography, spiral CT scanning is accurate, less invasive, less expensive, more widely available, and leads directly to therapeutic decisions. ${ }^{2}$ The role of thoracic CT scanning for other clinical presentations is less well defined.

The optimal assessment of clinical impact is a randomised study of CT scanning as an add-on test in similar patients and the use of gold standards to determine accuracy. This approach is challenging because of the widespread dissemination and acceptance of CT scanning to investigate chest diseases. For example, in a randomised study of CT scanning versus mediastinoscopy for nonsmall cell lung cancer, $1120(42.4 \%)$ of the 2639 ineligible patients had already had a CT scan taken or were considered to have absolute indications for CT scanning. ${ }^{3}$ Also, gold standards are not available for many clinical presentations for which thoracic CT scanning is indicated. Most of the data currently available are from retrospective studies on small numbers of patients. ${ }^{4}$ Retrospective studies provide weaker evidence for decision making than prospective studies, partly because of the exclusion of cases in which the CT scan result was negative, thus introducing a "verification bias". ${ }^{5}$ In a prospective survey of physicians ordering thoracic CT scans at a university affiliated tertiary care hospital, the most common diagnoses or symptom presentations prior to the scan were lung malignancy, interstitial lung disease, bronchiectasis, and haemoptysis. ${ }^{6}$ Haemoptysis is a clinical presentation with no gold standard to determine accuracy. Studies of lung cancer with mediastinal involvement and interstitial lung disease, where there are gold standards (tissue pathology), and haemoptysis illustrate the uncertainties of measuring the clinical impact of thoracic CT scanning.

\section{Lung malignancy}

Thoracic CT scanning is commonly used to assess lung masses or nodules and to stage the extent of mediastinal disease. A meta-analysis of 42 studies of lung cancer that staged the mediastinum by CT scanning reported a sensitivity of 0.79 and a specificity of 0.78 for detecting metastatic nodal disease. ${ }^{7}$ The sensitivity estimate has been confirmed prospectively by a randomised trial of 685 patients evaluated for potentially resectable lung cancer. ${ }^{3}$ A comparison of management strategies including mediastinoscopy versus CT scanning prior to thoracotomy showed a sensitivity of 0.78 for CT scanning and a slightly lower specificity of 0.69 . The primary objective of this multicentre Canadian Lung Oncology Group (CLOG) study was to identify the best strategy to avoid non-curative thoracotomies. There were non-significant trends in the CT group for preventing thoracotomy without cure (relative risk $0.95,95 \%$ CI 0.75 to 1.19 ), prevention of thoracotomy for the 45 $(6.6 \%)$ patients with benign disease (relative risk $0.42,95 \%$ CI 0.12 to 1.13), and a decreased overall cost for services (mediastinoscopy was more expensive than CT scanning by $\$ 708,95 \% \mathrm{CI}-\$ 723$ to $\$ 2140)$. $^{3}$

A randomised trial is a powerful approach to resolving a controversial clinical question when it has the power to detect a difference. However, as the CLOG study ${ }^{3}$ demonstrates, randomised clinical trials are time consuming (almost five years from initial recruitment until completion of follow up), costly, and logistically difficult. Although the results of the CLOG study are not definitive, the authors make a reasoned argument for CT scanning first, followed by mediastinoscopy, for patients with lymph nodes larger than $1 \mathrm{~cm}$. Several other studies have recommended mediastinoscopy, even with a negative CT scan, because of the relative insensitivity of CT scanning. ${ }^{89}$ In the absence of definitive evidence, many clinicians will continue to evaluate their patients empirically according to the accessibility of CT scanning and the pattern of management particular to their institution. ${ }^{10}$

\section{Interstitial lung disease}

The development of high resolution CT (HRCT) scanning has allowed greater accuracy in detecting interstitial lung disease and has also identified patterns that are diagnostic. ${ }^{4}$ CT scans can impact on clinical management by making firm diagnoses and therefore avoiding biopsies, by identifying patients who are likely to respond to treatment, and by directing biopsy samples to obtain a maximal yield. CT scanning demonstrates the extent and location of representative disease more accurately than chest radiography. ${ }^{1112} \mathrm{~A}$ radiological/pathological comparison in 458 patients with chronic diffuse infiltrative lung diseases 
found that $9.6 \%$ of chest radiographs taken before the biopsy specimens were interpreted as normal. ${ }^{13}$ Direct comparisons between CT scans and chest radiographs for diffuse infiltrative disease, using gold standards of biopsy specimens in most cases, have shown CT scanning to be more accurate for the diagnosis and detection of patterns, especially ground glass appearance. ${ }^{1114}$

Tissue biopsy specimens are taken to make diagnoses and, for some conditions, to establish disease activity. The CT scan may also indicate whether a transbronchial biopsy specimen can establish the diagnosis. ${ }^{11}$ A study comparing transbronchial biopsy specimens with open lung biopsy specimens in 53 patients with interstitial lung disease showed that transbronchial biopsy specimens established a diagnosis in only 20 (38\%) while a specific diagnosis was made with open lung biopsy specimens in $92 \%$ of the others. ${ }^{15}$ However, there are no prospective or randomised studies to determine the clinical and cost effectiveness of CT scanning before a planned biopsy procedure. In cases where sarcoidosis or lymphangitic carcinomatosis are clinically and radiologically suspected, transbronchial biopsy specimens should have a good yield whether or not a CT scan is performed.

Disease activity, especially when there is evidence of inflammation, can be used to make decisions about instituting treatment. Knowledge of disease activity from a non-invasive diagnostic test such as a CT scan may be important for patients at risk of complications from open biopsies and anti-inflammatory therapy. CT findings of a ground glass pattern in patients with cryptogenic fibrosing alveolitis correlated well with four year survival and also correlated with response to treatment in a small subgroup of steroid treated patients. ${ }^{16}$ The measure of agreement beyond chance (the kappa statistic) was only 0.54 between the two experienced radiologists ${ }^{16}$ which raises concerns about how CT scanning would perform in centres with less experienced chest radiologists. In a highly selected group of patients with biopsy proven idiopathic pulmonary fibrosis, chest radiographs and HRCT scans were normal in three of 25 patients with pathological evidence of disease. ${ }^{17}$ These three patients were all treated with prednisone and cyclophosphamide (two patients) without improvement. Although the patients were symptomatic, intervention at this stage seemed to have little impact and suggests that abnormalities on the CT scan which correlate with some pulmonary function tests ${ }^{1819}$ are useful in deciding when to intervene medically or surgically.

\section{Haemoptysis}

Haemoptysis is frequently encountered in a referral setting. After the clinical history and physical examination, chest radiography is the investigation of first choice. An approach taken by several authors is to group the results of chest radiography as localising, non-localising, or normal. ${ }^{2021}$ The latter two groups especially merit further investigation, including bronchoscopy to rule out a central malignancy and to localise a bleeding site. Three prospective studies have evaluated the role of CT scanning in addition to chest radiography and fibreoptic bronchoscopy. ${ }^{21-23}$

Millar and colleagues prospectively studied 40 patients with haemoptysis who had normal chest radiographs and fibreoptic bronchoscopic examinations. ${ }^{22}$ Each patient had a contrast enhanced CT scan and abnormalities were found in 20 cases: seven bronchiectasis, four malignancy, one histiocytosis $\mathrm{X}$, one arteriovenous malformation, and six with miscellaneous diagnoses. Although $50 \%$ of undiagnosed patients had CT abnormalities, the impact of CT scanning on the outcomes is questionable. If bronchiectasis was the working diagnosis prior to the CT scan, sub- sequently confirmed by CT scanning and the patient had no further bleeding episodes, how is the impact of CT scanning on management measured? A diagnosis of bronchiectasis made after a CT scan may result in fewer investigations and change follow up management, or the extent of the disease may alter a planned surgical procedure. These outcomes are not reported in Millar's study but are relevant when deciding if thoracic CT scanning is useful in the investigation of haemoptysis.

McGuinness and colleagues compared the diagnostic yield from HRCT scans, chest radiographs, and fibreoptic bronchoscopy in 57 consecutive patients with haemoptysis. ${ }^{21}$ Eight of the chest radiographs were normal, 38 showed non-localising and 11 localising disease. The CT scans were diagnostic in $25 \%$ of the normal radiographs, and in $68 \%$ of the non-localising and $64 \%$ of the localising radiographs. The diagnostic yield from fibreoptic bronchoscopy was $43 \%$. The authors recommend HRCT scanning before bronchoscopy in all patients who present with haemoptysis. The rationale for doing a CT scan first is the potential to do fewer bronchoscopies and to guide the bronchoscopist when abnormalities need further evaluation. ${ }^{24}$ It could be argued, however, that neither the study design nor the data support this conclusion, especially in patients with a normal chest radiograph. The diagnostic yield following CT scanning in this study for patients with a normal radiograph was only $25 \%$ compared with $40 \%$ for fibreoptic bronchoscopy.

HRCT scanning was compared with fibreoptic bronchoscopy in 91 patients studied by Set and colleagues. ${ }^{23}$ The case mix included $34(37 \%)$ malignancies and 42 $(46 \%)$ with negative chest radiographs. In the latter group, two malignancies were detected by both CT scanning and fibreoptic bronchoscopy. The overall yield in those with a negative chest radiograph was equivalent, but CT scanning detected bronchiectasis in five patients whereas fibreoptic bronchoscopy diagnosed bronchitis in four. The investigators recommended CT scanning as an initial investigation for patients with a normal chest radiograph and a low risk for malignancy (age $<40$, non-smokers), and bronchoscopy as the initial investigation for patients suspected of malignancy with a relevant abnormal chest radiograph.

These three prospective studies are consistent in recommending the use of CT scanning before fibreoptic bronchoscopy in patients with non-massive haemoptysis and normal chest radiographs. ${ }^{21-23}$ These recommendations are based on diagnostic information that may not change or influence management. ${ }^{25} \mathrm{~A}$ randomised trial that measures clinical outcomes and costs for each diagnostic strategy is needed to determine the optimal approach to management.

\section{Conclusions}

Although there have been numerous recommendations to assess prospectively the clinical impact of thoracic CT scanning on patient outcomes, ${ }^{42426-28}$ the introduction of new technology such as spiral CT scanning will lead to another cycle of diagnostic assessment. ${ }^{29} \mathrm{CT}$ scanning can certainly impact greatly on the management of individual patients but the appropriate and optimal utilisation for various clinical presentations needs to be examined more rigorously. In 1976 one of the first clinical evaluations of CT scanning used a prospective before and after survey of physicians to measure diagnostic and therapeutic impact. ${ }^{30}$ Before and after studies are subject to biases that may affect validity but can generate preliminary results that should be confirmed by more rigorous studies. ${ }^{31}$ The randomised trial is the optimal methodology to evaluate the 
role of CT scanning for specific clinical presentations and to measure clinical and economic outcomes.

Respiratory Division

Department of Medicine,

M O TURNER

University of British Columbia and

Division of TB Control,

B.C. Centre for Disease Control,

Vancouver,

British Columbia V5Z 1L8, Canada

1 Sackett DL, Haynes RB, Guyatt GH, Tugwell P. Clinical epidemiology: basic science for clinical medicine. Boston: Little, Brown and Co, 1991. 2 Hansell DM, Padley SPG. Continuous volume computed tomography in pulmo

3 Canadian Lung Oncology Group. Investigation for mediastinal disease in patients with apparently operable lung cancer. Ann Thorac Surg 1995;60 1382-9.

4 Muller NL. Clinical value of high-resolution CT in chronic diffuse lung disease. AfR 1991;157:1163-70

5 Begg CB, Greenes RA. Assessment of diagnostic tests when disease verification is subject to selection bias. Biometrics 1983;39:207-15.

6 Turner MO, Archer BD. Computed tomography (CT) of the thorax: an audit and before/after survey of physicians. Am $\mathcal{7}$ Respir Crit Care Med 1995;151:A294.

7 Dales RE, Stark RM, Sankaranarayanan R. Computed tomography to stage lung cancer. Am Rev Respir Dis 1990;141:1096-101.

8 McLoud TC, Bourgouin PM, Greenberg RW, Kosiuk JP, Templeton PA, Shepard JO, et al. Bronchogenic carcinoma: analysis of staging in the mediastinum with CT by correlative lymph node mapping and sampling. mediastinum with CT by corr

9 Staples CA, Muller NL, Miller RR, Evans KG, Nelems B. Mediastinal nodes in bronchonic carcinoma: comparison between CT and medianodes in bronchogenic carcinoma: compar

10 Fergusson RI, Gregor A, Dodds R, Kerr G. Management of lung cancer in South East Scotland. Thorax 1996;51:569-74.

11 Mathieson JR, Mayo JR, Staples CA, Muller NL. Chronic diffuse infiltrative lung disease: comparison of diagnostic accuracy of CT and chest radiography. Radiology 1989;171:111-6.

12 Tung KT, Wells AU, Rubens MB, Kirk JME, du Bois RM, Hansell DM. Accuracy of the typical computed tomographic appearances of fibrosing alveolitis. Thorax 1993;48:334-8.

13 Epler GR, McLoud TC, Gaensler EA, Mikus JP, Carrington CB. Normal chest roentgenograms in chronic diffuse infiltrative lung disease. $N$ Engl f Med 1978;298:934-9.

14 Collins CD, Wells AU, Hansell DM, Morgan RA, MacSweeney JE, du Bois RM, et al. Observer variation in pattern type and extent of disease in fibrosing alveolitis on thin section computed tomography and chest radiography. Clin Radiol 1994;49:236-40.

15 Wall CP, Gaensler EA, Carrington CB, Hayes JA. Comparison of trans bronchial and open biopsies in chronic diffuse infiltrative lung diseases. Am Rev Respir Dis 1981;123:280-5.

16 Wells AU, Hansell DM, Rubens MB, Cullinan P, Black CM, du Bois RM The predictive value of appearances on thin-section computed tomography in fibrosing alveolitis. Am Rev Respir Dis 1993;148:1076-82.

17 Orens JB, Kazerooni EA, Martinez FJ, Curtis JL, Gross BH, Flint A, et al. The sensitivity of high-resolution CT in detecting idiopathic pulmonary fibrosis proved by open lung biopsy: a prospective study. Chest 1995;108: $109-15$.

18 Terriff BA, Kwan SY, Chan-Yeung MM, Muller NL. Fibrosing alveolitis: chest radiography and $\mathrm{CT}$ as predictors of clinical and functional impairment at follow-up in 26 patients. Radiology 1992;184:445-9.

19 Wells AU, Rubens MB, du Bois RM, Hansell DM. Serial CT in fibrosing alveolitis: prognostic significance of the initial pattern. $A f R$ 1993;161: 1159-65.

20 Poe RH, Israel RH, Marin MG, Ortiz CR, Dale RC, Wahl GW, et al. Utility of fiberoptic bronchoscopy in patients with hemoptysis and a nonlocalizing chest roentgenogram

21 McGuinness G, Beacher JR, Harkin J, Garay SM, Rom WN, Naidich DP. Hemoptysis: prospective high-resolution CT/bronchoscopic correlation. Chest 1994;105:1155-62.

22 Millar AB, Boothroyd AE, Edwards D, Hetzel MR. The role of computed tomography (CT) in the investigation of unexplained haemoptysis. Respir Med 1992;86:39-44

23 Set PAK, Flower CDR, Smith IE, Cahn AP, Twentyman OP, Shneerson JM. Hemoptysis: comparative study of the role of CT and fiberoptic bronchoscopy. Radiology 1993;189:677-80.

24 Muller NL. Hemoptysis: high resolution CT vs bronchoscopy. Chest 1994; 105:982-3.

25 Haponik EF, Britt EJ, Smith PL, Bleecker ER. Computed chest tomography in the evaluation of hemoptysis: impact on diagnosis and treatment. Chest 987;91:80-5.

26 Marshall TJ, Flower CDR, Jackson JE. The role of radiology in the investigation and management of patients with haemoptysis. Clin Radiol 1996;51:391-400.

27 Smith IE, Flower CDR. Review article: imaging in bronchiectasis. $\mathrm{Br} f$ Radiol 1996;69:589-93.

28 DiMarco AF, Briones B. Is chest CT performed too often? Chest 1993;103: 985-6.

29 Van der Bruggen-Bogaarts BAHA, van der Bruggen HMJG, van Waes PFGM, Lammers JWJ. Assessment of bronchiectasis: comparison of HRCT and spiral volumetric CT. 7 Comput Assist Tomogr 1996;20:15-19.

30 Wittenberg J, Fineberg HV, Black EB, Kirkpatrick RH, Schaffer DL, Iked MK, et al. Clinical efficacy of computed body tomography. AfR 1978 ; 131:5-14

31 Guyatt GH, Tugwell PX, Feeny DH, Drummond MF, Haynes RB. The role of before-after studies of therapeutic impact in the evaluation of diagnostic technologies. F Chronic Dis 1986;39:295-304. 